Article

\title{
Enduring and Stable Surface Dielectric Barrier Discharge (SDBD) Plasma Using Fluorinated Multi-Layered Polyimide
}

\author{
Dongliang Bian ${ }^{1}$ and Yun $\mathrm{Wu}^{2, *}$ (1) \\ 1 Science and Technology on Plasma Dynamics Laboratory, Air Force Engineering University, \\ Xi'an 710038, China; biand11990@163.com (D.B.) \\ 2 Institute of Aero-engine, School of Mechanical Engineering, Xi'an Jiaotong University, Xi'an 710049, China \\ * Correspondence: wuyun1223@126.com
}

Received: 11 May 2018; Accepted: 31 May 2018; Published: 2 June 2018

check for updates

\begin{abstract}
In this work, multi-layered polyimide (PI) films were surface fluorinated at $328 \mathrm{~K}$ and $0.05 \mathrm{MPa}$ using $\mathrm{F}_{2} / \mathrm{N}_{2}$ mixture with $20 \% \mathrm{~F}_{2}$ by volume, for a fluorination time of 0,30 and $60 \mathrm{~min}$, respectively. Then, they were subjected to discharge plasma as barrier dielectrics of surface dielectric barrier discharge (SDBD) at ambient atmospheric air. The dielectric lifetime of SDBD greatly extends after 60 min surface fluorination. In addition, optical emission spectroscopy (OES) results indicate that during the plasma processing, SDBD with fluorinated PI can obtain more stable plasma parameters, including gas temperature and electron temperature. Dielectric surface properties were further evaluated by infrared thermography, scanning electron microscope (SEM), and X-ray photoelectron spectroscopy (XPS). It is considered that both physical and chemical effects lead to the extension of dielectric lifetime. The physical effect is reflected in low surface temperature and increased surface roughness, while the chemical effect is reflected in the graft of fluorine groups.
\end{abstract}

Keywords: surface fluorination; SDBD; discharge characteristic; multi-layered polyimide

\section{Introduction}

Nowadays, atmospheric plasma sources have drawn more attention due to their many advantages, such as having no need for vacuum equipment, being a low-cost and simple system, and being easy to be operated [1]. Among various types of plasma sources, surface dielectric barrier discharge (SDBD) has attracted significant attention because it can produce stable discharge with very simple configuration. Thus, it has been characterized [2,3] and successfully applied as a plasma actuator in various aerodynamic fields, such as active flow control [2,4], heat generation for de-icing and anti-icing [5], as well as film cooling [6]. Besides, it can be used as a plasma-based chemical reactor in many environmental applications, such as ozone generation $[7,8]$, decomposition of volatile organic compounds (VOCs) [9], $\mathrm{NO}_{x}$ conversion [10], and inactivation of killing bacteria [11]. Generally, SDBD plasma device is made of a dielectric plate with two metallic electrodes placed on each side. Supplied with an AC voltage or a pulsed voltage, non-thermal plasma is created on the surface of dielectric. Typical barrier dielectric materials include ceramics, polymers, quartz, and glass.

Compared with traditional ceramics or glasses, polymers possess the advantage of flexibility so that they can be easily adhered to the curved surface, such as the leading edge of the wings, aero engine blades, and many cylindrical-shaped plasma reactors. However, it has been proved that polymers have poor resistance to the plasma environment; the intense bombardment of energetic active species (ions, electrons, UV photons, etc.) can erode them [12,13]. As a result, lack of durability becomes a serious drawback for polymer-based SDBD plasma devices. Pons et al. [12] showed that degradation 
of two sorts of polymers (Poly methyl methacrylate and Polyvinyl chloride) occurred when they were exposed to $10 \mathrm{~min}$ of plasma operation in ambient air. Hanson et al. [14] and Ndong et al. [15] experimentally showed that degradation of PI-based actuators was accompanied by an increase of power consumption after plasma processing. Rigit et al. [16] found that plasma actuators manufactured from PCBs were visually shown to degrade and fail in some instances.

From the above reports, it can be concluded that appropriate pretreatment of the polymers needs to be done to obtain better performance of SDBD plasma devices. As one of the most effective approaches to the chemical modification of polymer surfaces, direct fluorination using fluorine gas has been widely developed from fundamental research to industrial applications [17]. It has advantages such as outstanding surface properties, similar to the fluoropolymers that can be obtained without changing the bulk characteristics of the starting polymer. The research works and applications are mainly concentrated on the improvements of the barrier properties, wettability, adhesiveness, chemical stability or biocompatibility of polymers $[18,19]$ and dealing with the electrical properties of polymers. For example, An et al. [20,21] indicated that surface fluorination of PE has a significant influence on the charge injection and accumulation. Du et al. $[22,23]$ found that surface fluorination is an effective method for modulating the electrical properties and restraining the surface charge and space charge accumulation of the PI film.

In recent years, several groups have modified polymers' surface chemical composition with the help of plasma in order to increase their adhesion or hydrophilicity [24-27]. During plasma processing, ion bombardment breaks chemical bonds in the polymer's backbones, while radicals enable functional groups to be grafted onto the polymer's surface. The functional groups improve the polymer's wettability and adhesion by inducing an increase of its surface energy. Similar to plasma surface modification, when a SDBD plasma device is powered, the produced active species in the discharge region also interact with the dielectric surface. Thus, the existing research methods of plasma surface modification may provide a new route to investigate the degradation issue of polymer-based plasma devices. In our previous work [28], $\mathrm{PI} / \mathrm{Al}_{2} \mathrm{O}_{3}$ nanocomposite was fabricated and used as a dielectric of the plasma actuator. Compared to the conventional PI-based actuator, both the dielectric lifetime was enhanced and the mechanical performance was improved. The major purpose of the present investigation is to understand the effects of varying fluorination time on the characteristics of PI-based SDBD plasma devices. Firstly, discharge properties including power consumption and dielectric capacitance were evaluated. Then, dielectric lifetimes, OES, and surface temperature distribution was measured and compared. Complementarily, in-depth studies of surface morphology and chemical composition by the way of SEM and XPS were conducted to characterize the surface properties of the dielectrics.

\section{SDBD Device and Experimental Set up}

\subsection{SDBD Device}

Five-layer PI films were chosen as dielectric barriers in this work, bonded with silicone adhesive. The PI film had a thickness of $50 \mu \mathrm{m}$ and an area of $50 \times 50 \mathrm{~mm}^{2}$. A $30 \mu \mathrm{m}$ thickness silicon adhesive was obtained from 3M Co. Ltd., Hongkong, China. The total thickness of the barrier dielectric was $0.37 \mathrm{~mm}$. Surface fluorination of the dielectrics was carried out in a stainless reactor kettle with polytetrafluoroethylene lining at about $328 \mathrm{~K}\left(55^{\circ} \mathrm{C}\right)$ using a $\mathrm{F}_{2} / \mathrm{N}_{2}$ mixture with $20 \% \mathrm{~F}_{2}$ by volume [22]. After evacuation and purification with nitrogen gas more than three times, the reactive gas mixture was introduced slowly into the vessel until the mixture pressure in the vessel had reached $0.05 \mathrm{MPa}$ (500 mbar). The fluorination time was 30 and $60 \mathrm{~min}$, respectively. After treatment, the reactive gas mixture was purged from the vessel with nitrogen.

Once the fluorination process was completed, electrodes were fabricated using copper tapes with a thickness of $70 \mu \mathrm{m}$, as shown in Figure 1a. The width of the exposed and encapsulated electrode was 5 and $25 \mathrm{~mm}$, respectively. The tips of the encapsulated electrode were rounded with a diameter 
of $0.8 \mathrm{~mm}$. There was no gap between the two edges of the electrodes. Their effective span length (along which plasma was generated) was $30 \mathrm{~mm}$. The encapsulated electrodes were covered in Kapton tape to prevent unwanted plasma formation. As shown in Figure $1 \mathrm{~b}-\mathrm{d}$, the top device (1\#) was based on the un-fluorinated PI. The middle device (2\#) was based on $30 \mathrm{~min}$ fluorinated PI. The bottom device (3\#) was based on 60 min fluorinated PI.

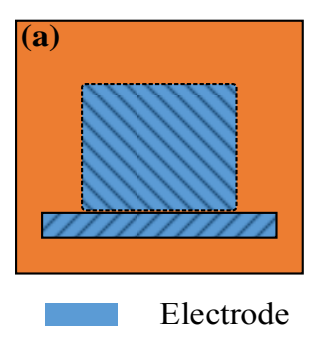

Multilayered PI dielectric

(b) 1\#

\section{(c) 2\#}

\section{(d) 3\#}

Fluorination layer

Encapsulated layer

Figure 1. Top view of Surface Dielectric Barrier Discharge (SDBD) plasma device (a) and cross section of SDBD plasma devices with un-fluorinated PI (b), 30 min fluorinated PI (c) and 60 min fluorinated PI (d); Not scale.

\subsection{Experimental Setup}

The experimental setup is schematically illustrated in Figure 2a, which is composed of an AC power supply, a SDBD plasma device, an electrical measurement system, and optical and thermal detection systems. The AC power (CTP-2000K, Suman Co., Nanjing, China) can supply an adjustable high sine peak to peak voltage $\left(V_{\mathrm{pp}}\right)$ up to $30 \mathrm{kV}$, with a power frequency $(f)$ in a range of $4-18 \mathrm{kHz}$. Surface plasma was generated near the exposed electrode. The photographs were captured using a Nikon D7000 digital camera (Tokyo, Japan). The applied voltage was measured by using a high voltage probe (Tektronix P6015A, Beaverton, OR, USA). Traces of the voltage across the plasma device and the capacitor probe were displayed and recorded using an oscilloscope (DPO4014, Tektronix Co., Beaverton, OR, USA). In order to reduce the interferences of discharge pulses on the detection system and other instruments, the power supply was placed in a shielding box, which was connected to the ground. Figure $2 \mathrm{~b}$ shows the top view of the surface plasma, where " $x$ " is a stream-wise direction (i.e., parallel to a streamer channel), and " $y$ " is a span-wise direction (i.e., parallel to the exposed electrode).

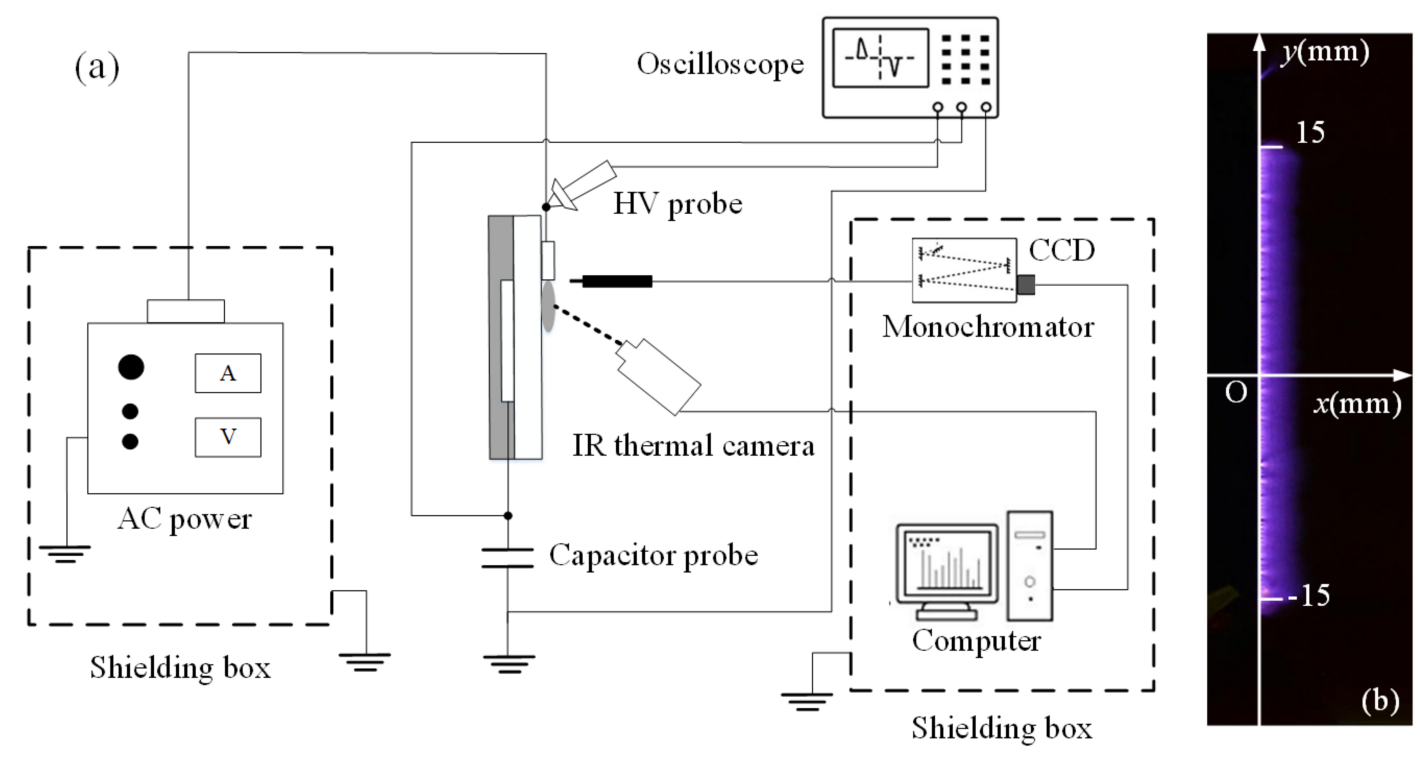

Figure 2. Schematic diagram of the experimental setup (a) and top view of discharge plasma (b). 
Infrared radiation characterization was conducted by measuring the surface temperature using a thermal camera Systems (SC7000, FLIR Inc., Portland, OR, USA) in the spectral range of 7.7-9.3 $\mu \mathrm{m}$, as was earlier described in Refs. [29,30]. The camera was placed $20 \mathrm{~cm}$ in front of the discharge. For each case, the device was run for a duration of $120 \mathrm{~s}$ and then switched off for $30 \mathrm{~s}$. The thermal camera and the computer then recorded the distribution of the surface temperature. Before the test, the surface emissivity was determined experimentally by simultaneously recording the temperature measured through the thermal camera and a thermocouple. In this case, the discharge was turned off and the dielectric was heated by an external source. Emissivity was found to be $\varepsilon=0.83 \pm 0.02$ when temperature ranged from 15 to $80^{\circ} \mathrm{C}$. OES was exploited to investigate excited active species generated in the SDBD plasma devices. The optical emission spectra were collected by a charge-coupled device spectrometer (Avantes 2048, Apeldoorn, Netherlands) through an optical fiber, located $5 \mathrm{~mm}$ above the surface of the dielectric layer, perpendicular to the plasma devices, and fixed in front of the generated plasma. The integration time of spectrograph was set to be $2000 \mathrm{~ms}$. Optical emission experiments were performed in a dark room and the background noise was measured before each test and subtracted before post-processing. As shown in Figure 2b, each condition was measured 30 times, at the scope $x=0 \mathrm{~mm}$ and $y=-15-15 \mathrm{~mm}$, the emission intensities were averaged.

Following the sputter coating of the films with gold, the surface morphologies of the dielectrics were observed using a scanning electron microscope (SEM, Zeiss Supra55, Oberkochen, Germany). $\mathrm{X}$-ray photoelectron spectroscopy (Bestec, Berlin, Germany) employing a monochromatic Al K radiation $(1486.6 \mathrm{eV})$ operated at $5 \mathrm{kV}$ and $10 \mathrm{~mA}$ in $10^{-10}$ mbar was used to determine the surface chemical structures of the dielectrics.

\subsection{Power Consumption and Dielectric Capacitance Calculation}

Measurements of the power consumption were conducted using a capacitor probe for the purpose of integrating the charge-voltage $(Q-V)$ cyclograms (or Lissajous figures), which has been elaborated in Refs. $[4,14,31]$. As shown in Figure 2, a ceramic capacitor probe with capacitance $\left(C_{\mathrm{pc}}\right)$ of $10 \mathrm{nF}$ was placed between the encapsulated electrode and the ground. The voltage across the capacitor probe $\left(V_{\mathrm{pc}}\right)$ can be measured directly through an oscilloscope. The instantaneous charge, $Q(t)$, was the product of $V_{\mathrm{pc}}(t)$ and $C_{\mathrm{pc}}$. The input voltage and charge values were plotted against each other to form a closed curve. The area equals to the consumed discharge energy per cycle $E_{\mathrm{k}}$, which can be calculated by:

$$
E_{\mathrm{k}}=\oint_{k} C_{\mathrm{pc}} V_{\mathrm{pc}}(t) d V=\oint_{k} Q(t) d V
$$

The consumed power $P$ was the product of $E_{\mathrm{k}}$ and $f$ :

$$
P=E f=\frac{f}{K} \sum_{k=1}^{k} E_{\mathrm{k}}
$$

In this work, 100 cycles of Lissajous figure data were calculated to obtain the averaged $E_{\mathrm{k}}$; the standard deviation was $\leq 3 \%$ for all cases. The consumed power was further calculated through the product of $f$ and the averaged $E_{\mathrm{k}}$. Additionally, Lissajous figure can also be utilized to analyze the discharge capacitance of the PI-based device [31]. As shown in Figure 3, the capacitance was equal to $\mathrm{d} Q / \mathrm{d} V$. Two typical capacitance values were the cold capacitance $\left(C_{0}\right)$ and the effective capacitance $\left(C_{\text {eff }}\right)$, which corresponded to the cases when plasma was absent and present, respectively. The calculation method of $C_{0}$ and $C_{\text {eff }}$ was based on a least squares fit of a straight line over the constant-slope regions, more details have been described in Ref. [14]. The uncertainty of the calculated capacitances was less than $3 \%$. It should be pointed out that $C_{0}$ value of the un-fluorinated device can also be measured through a multimeter, and the result agreed well with this method. According to Lissajous figure data, the calculated $C_{0}$ and $C_{\text {eff }}$ were $4.5 \pm 0.1$ and $13.5 \pm 0.3 \mathrm{pF}$, which were three orders and two orders lower than the value of $C_{\mathrm{pc}}$, respectively. Thus, on the basis of the 
selection criteria proposed by Kriegseis [31], the capacitance probe was sufficient large and feasible in present work.

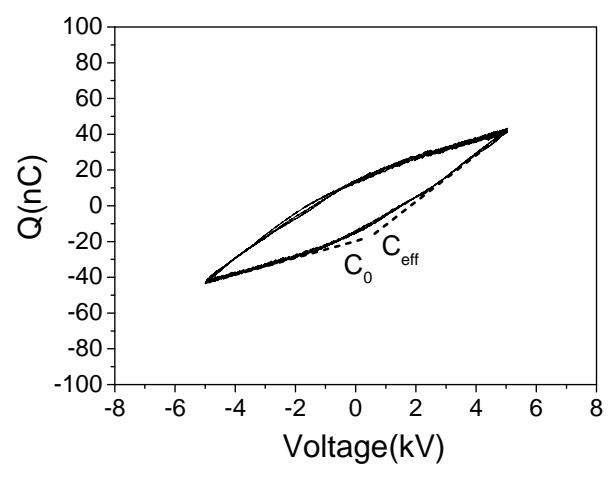

Figure 3. Lissajous figure of the un-fluorinated device $\left(V_{\mathrm{pp}}=10 \mathrm{kV}, f=6 \mathrm{kHz}\right)$.

\section{Results and Discussion}

\subsection{Discharge Properties}

Figure 4 shows the time dependence of the consumed power for three plasma devices. It can be seen that the consumed power values of the two fluorinated devices were higher than that of the un-fluorinated one at the aging time of $0 \mathrm{~h}$, then, the consumed power of the three devices increased with the aging time; this was mainly because the plasma was situated nearer the grounded electrode with the degradation of the top PI layer, and therefore in a region where the expected electric field strength was higher [14]. Besides, the power data in case of $1 \#$ device can be well fit by a simple linear Function (3), the calculated $A$ and $B$ values were 0.88 and 36.54 , respectively. A second-order polynomial Function (4) can be used to fit the cases of 2\# and 3\# devices, the calculated $C, D$ and $E$ values were $0.024,0.027,38.17$ for $2 \#$ device and $0.017,-0.017,38.72$ for $3 \#$ device. The fitted results show that the plasma processing had less effects on the consumed power values of fluorinated devices. For instance, after aging time of $20 \mathrm{~h}$, the consumed power of 3\# device increased by about $18 \%$, which was about $46 \%$ lower than the case of $1 \#$ device. In Ref. [14], a method using a coating of Polydimethylsiloxane oil was proposed to prevent erosion of the PI-based actuator. Similar phenomenon of slower increase rate of the consumed power has also been observed.

$$
f(x)=A x+B
$$

where $A$ and $B$ are free parameters.

$$
f(x)=C x^{2}+D x+E
$$

where $C, D$ and $E$ are free parameters.

Lissajous figures corresponding to four different discharge cases marked in Figure 4 are shown in Figure 5a,b, for 1\# device and 3\# device, respectively. It is seen that the shapes of Lissajous figures did not change apparently. However, the enclosed area was expanded for both cases after aging and the case of $1 \#$ device seemed more pronounced, which led to higher $E_{\mathrm{k}}$ and $P$. The calculating results of $C_{0}$ and $C_{\text {eff }}$ values at different aging times for the three devices are given in Figure $5 c, d$, along with the fits based on Function (3). In case of $C_{0}$ fitting, the values of $A$ were $-8 \times 10^{-4}, 0.012$ and 0.015 , while the values of $B$ were $4.50,4.38$ and 4.28 , for the cases of $1 \#, 2 \#$ and $3 \#$ devices, respectively. In case of $C_{\text {eff }}$ fitting, the values of $A$ were $0.188,0.098$ and 0.049 ; while the values of $B$ were 13.58 , 13.75 and 13.89, for the cases of 1\#, 2\# and 3\# devices, respectively. Based on the fitted lines, it can be seen that for $1 \#$ device, $C_{0}$ values remained almost unchanged with the aging time, while $C_{\text {eff }}$ increased 
significantly from $13.5 \pm 0.3$ to $17.3 \pm 0.3 \mathrm{pF}$ (about $28 \%$ higher). Compared to $1 \#$ device, both $C_{0}$ and $C_{\text {eff }}$ values had slight increase for $2 \#$ and $3 \#$ devices. Taking $3 \#$ device as an example, after $20 \mathrm{~h}$ of plasma discharge aging, $C_{0}$ values increased from $4.3 \pm 0.1$ to $4.6 \pm 0.1 \mathrm{pF}$, while $C_{\text {eff }}$ values increased from $14 \pm 0.3$ to $14.9 \pm 0.3 \mathrm{pF}$ (about $6.4 \%$ higher), which was much lower than variation range of $1 \#$ device. According to Ref. [14], the increase range of $C_{\text {eff }}$ value directly revealed the degradation degree of the dielectric beneath discharge plasma; it can be concluded that when using fluorinated PI as a dielectric, the dielectric degradation was effectively inhibited.

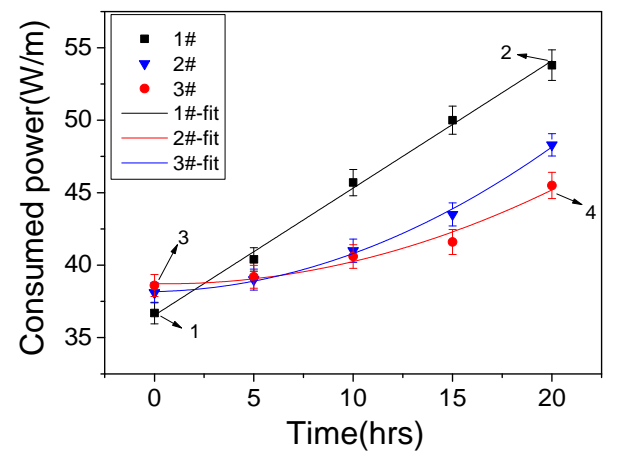

Figure 4. Consumed power of the three plasma devices as a function of the aging time.
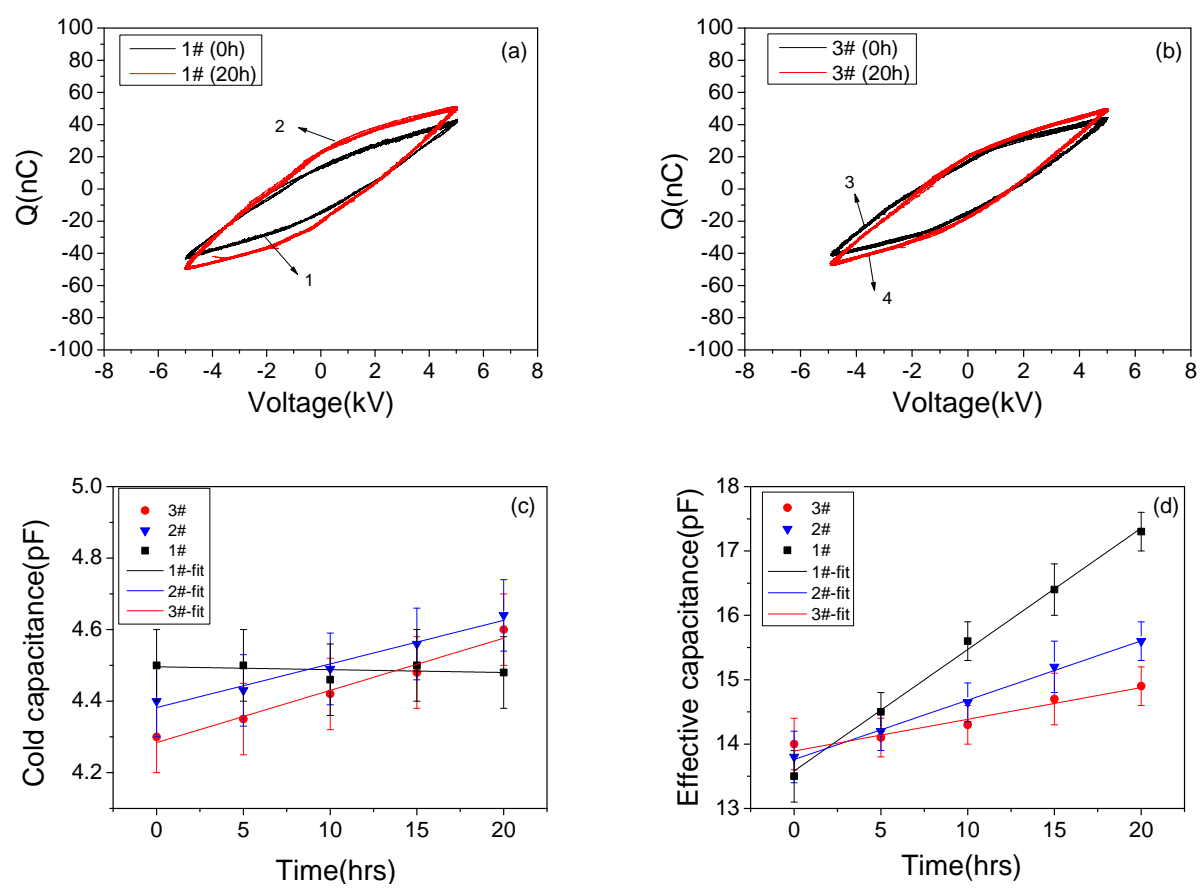

Figure 5. Lissajous figures of un-fluorinated device (a) and $60 \mathrm{~min}$ fluorinated device (b) at the aging times of 0 and $20 \mathrm{~h}$, cold capacitance (c) and effective capacitance (d) as a function of the aging time for the three devices.

\subsection{Dielectric Lifetime}

The results of lifetime measurements for PI dielectric with different fluorination time are shown in Figure 6. Two different applied voltages with the same frequency were set as the aging condition: $10 \mathrm{kV}$, $6 \mathrm{kHz}$ and $12 \mathrm{kV}, 6 \mathrm{kHz}$. For each condition, five samples were tested to obtain the average lifetime. As can be observed, for the same power supply parameter, longer fluorination time brought a gradual longer dielectric lifetime of the PI dielectric. At the applied voltages of 10 and $12 \mathrm{kV}$, dielectric lifetimes 
of the 60 min fluorinated PI were around 77 and $16.6 \mathrm{~h}$, about 3 and 2.6 times longer than the case of the un-fluorinated PI. Dielectric lifetimes of the $30 \mathrm{~min}$ fluorinated PI were about 58.2 and $12.5 \mathrm{~h}$, about 2.3 and 2 times longer than the case of the un-fluorinated PI. Also, for all these three dielectrics, it can be seen that dielectric lifetimes decreased obviously when the applied voltage was increased from 10 to $12 \mathrm{kV}$.

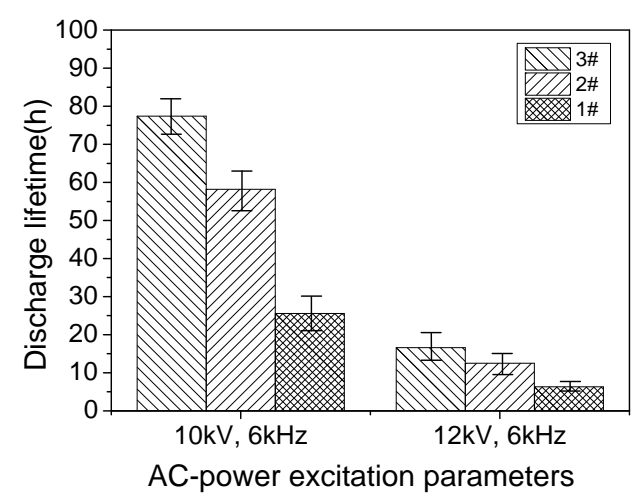

Figure 6. Dielectric lifetime of SDBD plasma devices with different dielectrics under the conditions of the two power supply parameters.

\subsection{Surface Temperature and Plasma Diagnosis}

Surface temperature of three devices at different aging times (0,10 and $20 \mathrm{~h})$ was measured using a thermal infrared camera. Figure 7 quantitatively gives the temperature distribution along the edge of the exposed electrode $(x=0,5$ and $10 \mathrm{~mm})$. For the three devices at different aging times, the $y$ direction distribution indicated a maximum temperature rise on the edge of the exposed electrode $(x=0 \mathrm{~mm})$. A gradual drop in temperature was observed on the downstream side of the electrode $(x=5$ and $10 \mathrm{~mm})$. Also, the temperature perturbation at $x=0 \mathrm{~mm}$ was strongest and the more uniform distribution appeared at a downstream location $(x=5$ and $10 \mathrm{~mm})$. It is further noted that the surface temperature value in the same positon gradually increased with the aging time, and the surface temperature variations of the un-fluorinated PI were more pronounced and affected by long plasma processing. For instance, after $20 \mathrm{~h}$ of discharge aging, the maximum temperature rise at the position of $x=0 \mathrm{~mm}$ was higher in the case of the un-fluorinated PI (about $19{ }^{\circ} \mathrm{C}$ ) than the cases of the 30 and 60 min fluorinated PI dielectrics (about 3.6 and $2.9^{\circ} \mathrm{C}$, respectively). At the position of $x=20 \mathrm{~mm}$, the maximum temperature of the un-fluorinated PI increases about $9{ }^{\circ} \mathrm{C}$, while no obvious variation shown in Figure 7c can be observed for the 60 min fluorinated PI.
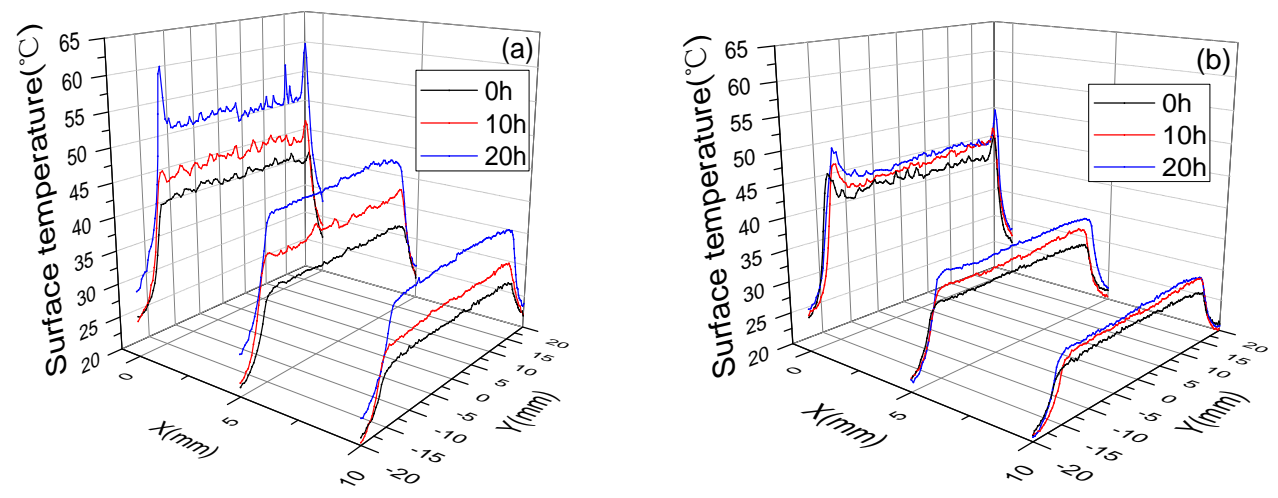

Figure 7. Cont. 


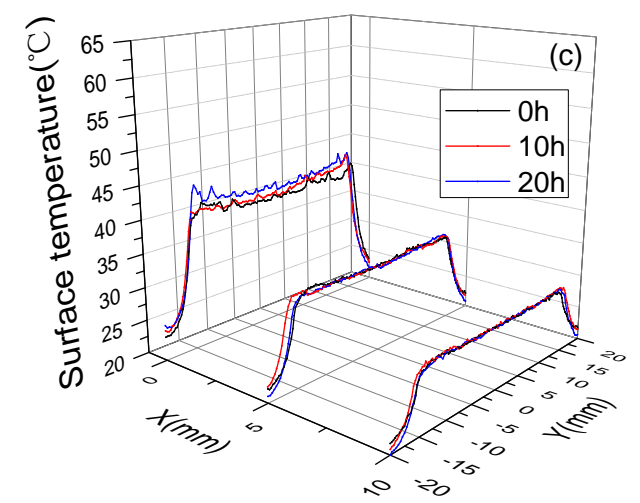

Figure 7. Surface temperature of the dielectrics with $0 \mathrm{~min}(\mathbf{a}), 30 \mathrm{~min}(\mathbf{b})$ and $60 \mathrm{~min}(\mathbf{c})$ surface fluorination, along the $Z$-direction at different $x$ position as a function of the aging time $\left(V_{\mathrm{pp}}=10 \mathrm{kV}\right.$, $f=6 \mathrm{kHz})$.

Optical emission spectroscopy (OES) is used to study discharge plasma. The emission spectrum in the range of 360-400 $\mathrm{nm}$ emitted from the plasma device with un-fluorinated PI is shown in Figure 8. The emission intensity was normalized with the intensity at $380.5 \mathrm{~nm}$. As expected with other atmospheric air non-equilibrium discharge [32], $\mathrm{N}_{2}$ peaks were dominant in the emission spectra. The major spectra came from the second positive system (SPS) of $N_{2}\left(C^{3} \Pi_{u} \rightarrow B^{3} \Pi_{g}\right)$ and the first negative system (FNS) of $\mathrm{N}_{2}{ }^{+}\left(\mathrm{B}^{2} \Sigma_{\mathrm{u}}{ }^{+} \rightarrow \mathrm{X}^{2} \Sigma_{\mathrm{g}}{ }^{+}\right)$. Typical peaks were identified according to Refs. [33-35], which included $N_{2}\left(C^{3} \Pi_{u} \rightarrow B^{3} \Pi_{g}, 2-4\right)$ at $371.1 \mathrm{~nm}, N_{2}\left(C^{3} \Pi_{u} \rightarrow B^{3} \Pi_{g}, 1-3\right)$ at $375.5 \mathrm{~nm}$, $\mathrm{N}_{2}\left(\mathrm{C}^{3} \Pi_{\mathrm{u}} \rightarrow \mathrm{B}^{3} \Pi_{\mathrm{g}}, 0-2\right)$ at $380.5 \mathrm{~nm}, \mathrm{~N}_{2}{ }^{+}\left(\mathrm{B}^{2} \Sigma_{\mathrm{u}}{ }^{+} \rightarrow \mathrm{X}^{2} \Sigma_{\mathrm{g}}{ }^{+}, 0-0\right)$ at $391.4 \mathrm{~nm}, \mathrm{~N}_{2}\left(\mathrm{C}^{3} \Pi_{\mathrm{u}} \rightarrow \mathrm{B}^{3} \Pi_{\mathrm{g}}, 2-5\right)$ at $394.3 \mathrm{~nm}$, and $\mathrm{N}_{2}\left(\mathrm{C}^{3} \Pi_{\mathrm{u}} \rightarrow \mathrm{B}^{3} \Pi_{\mathrm{g}}, 1-4\right)$ at $399.5 \mathrm{~nm}$.

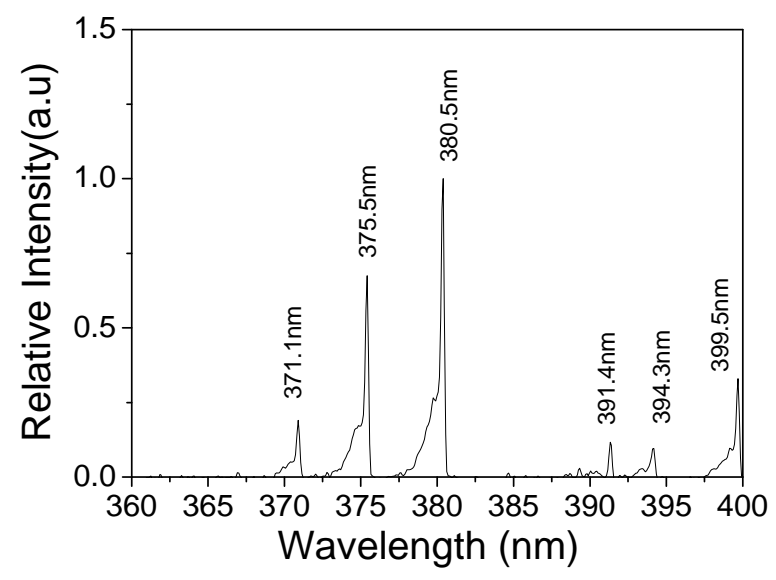

Figure 8. Normalized optical emission spectra of the plasma device with un-fluorinated PI $\left(V_{\mathrm{pp}}=10 \mathrm{kV}\right.$, $f=6 \mathrm{kHz})$.

The typical parameters such as $\mathrm{N}_{2}\left(\mathrm{C}^{3} \Pi_{\mathrm{u}}\right)$ vibrational temperature $\left(T_{\mathrm{vib}}\right)$, electron temperature $\left(T_{\mathrm{e}}\right)$ and $\mathrm{N}_{2}\left(C^{3} \Pi_{\mathrm{u}}\right)$ rotational temperature $\left(T_{\text {rot }}\right)$ are important parameters to evaluate plasma characteristics. The relative intensity ratio between 371.1 and $380.5 \mathrm{~nm}\left(I_{371.1} / I_{380.5}\right)$ can be used as an indicator of $T_{\mathrm{vib}}$; the relative intensity ratio between 391.4 and $380.5 \mathrm{~nm}\left(I_{391.4} / I_{380.5}\right)$ is used to obtain the temporal and spatial averaged $T_{\mathrm{e}}$ by the line-ratio technique of OES $[36,37]$. The variations of the two parameters at the discharge aging time of 0 and $20 \mathrm{~h}$ are shown in Figure $9 \mathrm{a}, \mathrm{b}$, respectively. For the three devices at the aging time of $0 \mathrm{~h}$, the $I_{371.1} / I_{380.5}$ and $I_{391.4} / I_{380.5}$ values remained almost the same (around 0.19 and 0.11 , respectively), suggesting that there were no conspicuous effects of surface fluorination on $T_{\text {vib }}$ and $T_{\mathrm{e}}$. When the discharge time increased to $20 \mathrm{~h}, I_{371.1} / I_{380.5}$ values of all devices 
shown in Figure 9a still had little changes (from around 0.19 to 0.20 ) during the plasma processing, suggesting that $T_{\text {vib }}$ had minor dependence on the discharge aging time. Nevertheless, for 1\# device shown in Figure $9 \mathrm{~b}$, the $I_{391.4} / I_{380.5}$ value increased apparently from $0.11(0 \mathrm{~h})$ to $0.164(20 \mathrm{~h})$, indicating a remarkable change of plasma characteristics - an increase in the number of high energy electrons and the average electron energy [38]. Compared to $1 \#$ device, the changes of the $I_{391.4} / I_{380.5}$ values for $2 \#$ and $3 \#$ devices were not obvious (from about 0.11 to 0.12 ). The different changes of $I_{391.4} / I_{380.5}$ values for three devices can be explained by the distribution of surface temperature. As shown in Figure $9 \mathrm{c}$, at the aging time of $0 \mathrm{~h}$, the temperature distribution was uniform along the edge of the exposed electrode. However, at the aging time of $20 \mathrm{~h}$, intense temperature perturbation can be clearly seen from Figure 9d, which was caused by the severe dielectric degradation of the un-fluorinated PI. As a result, the electrical field distortion became worse and more direct heat injected from the irregular glow spots to the dielectric surface, where the intense concentration of the ionization events occurred randomly [29]. The existence of glow spots in the negative-going cycle meant that the electrons transferred from the exposed electrode to the dielectric surface, combined with the fact that more discharge power was consumed by $1 \#$ device after $20 \mathrm{~h}$. It can be inferred that the discharge energy deposited on each electron transport channel also became higher. Therefore, $T_{\mathrm{e}}$ increased greatly because it was determined by the optical emission from the strong and bright discharge channels. At the same time, no noteworthy temperature perturbations can be seen in Figure 9f,h.
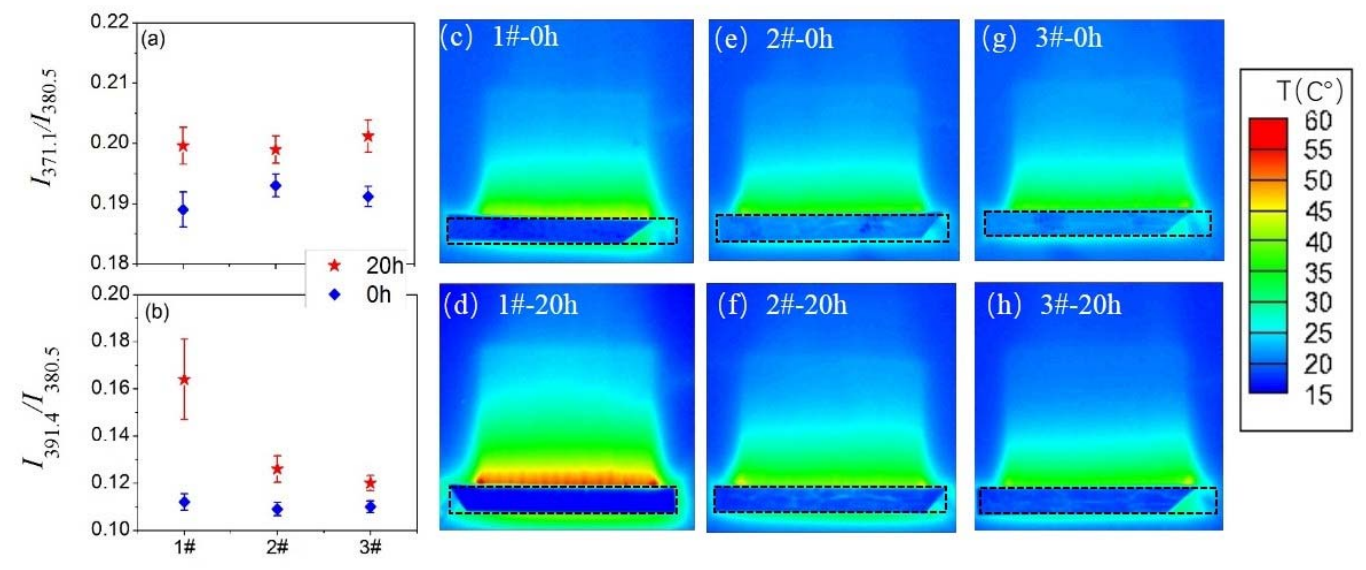

Figure 9. Variation of $I_{371.1} / I_{380.5}(\mathbf{a}), I_{391.4} / I_{380.5}(\mathbf{b})$, surface temperature distributions of $1 \#$ device at the aging times of $0 \mathrm{~h} \mathrm{(c)} \mathrm{and} 20 \mathrm{~h}(\mathbf{d}), 2 \#$ device at the aging times of $0 \mathrm{~h} \mathrm{(e)} \mathrm{and} 20 \mathrm{~h}(\mathbf{f}), 3 \#$ device at the aging times of $0 \mathrm{~h}(\mathrm{~g})$ and $20 \mathrm{~h}(\mathrm{~h})$.

The values of $T_{\text {rot }}$ are further determined by comparing the experimentally measured data to the theoretically calculated data with a least-square procedure. $T_{\text {rot }}$ is obtained by making the squared difference between measured and calculated normalized intensity minimum. In addition, gas temperature $\left(T_{\text {gas }}\right)$ can be regarded as being almost equal to $T_{\text {rot }}$ because the equilibrium between rotational and translational motion is easily obtained due to frequent and fierce collisions among the heavy particles [39]. The calculating results of three cases are shown in Figure 10, along with fits based on Function (3). The fitting values of $A$ were $1.04,0.60$ and 0.50 , while the values of $B$ were $370.40,370.65$ and 370.17 , for the cases of $1 \#, 2 \#$ and $3 \#$ devices, respectively. As presented in the embedded figure, the simulated spectrum at $T_{\text {rot }}=392 \mathrm{~K}$ fits the experimental one with good agreement. It can be seen that plasma discharge aging had more effects on $1 \#$ device than the other two devices. After $20 \mathrm{~h}$, the gas temperature of $1 \#$ device increased from about 370 to $390 \mathrm{~K}$; this was due to the increase of electron density and electron mean energy, more frequent collisions between electrons and heavy particles occurred, and therefore more energy transferred from electrons to heavy particles. At the same time, the increase ranges of $2 \#$ and $3 \#$ devices were lower than that of $1 \#$ device, suggesting that more stable plasma discharge can be obtained after dielectric surface fluorination. 


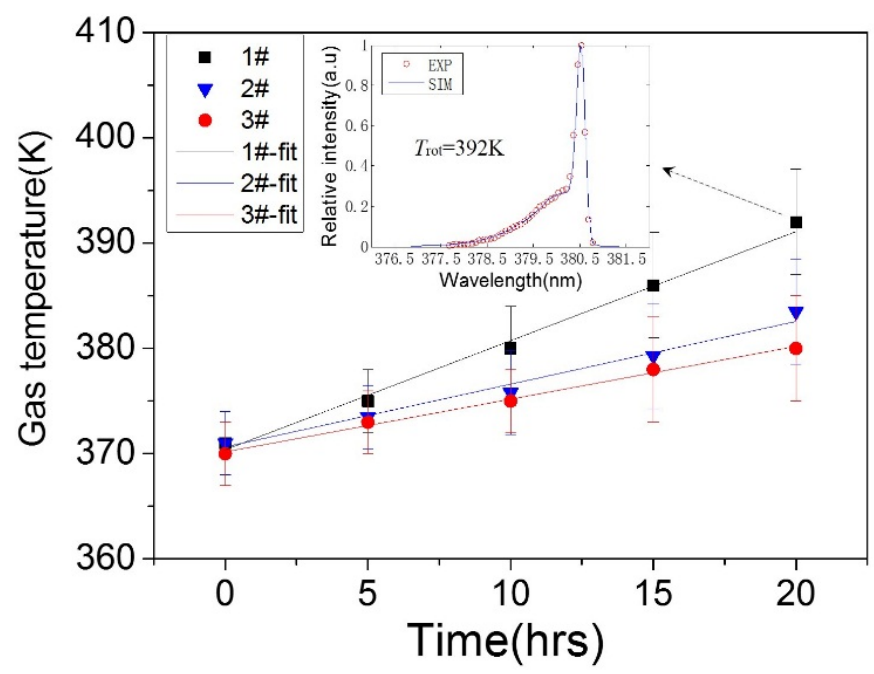

Figure 10. Effects of plasma discharge aging on the gas temperatures of the three devices.

\subsection{Surface Morphology and Chemical Structure}

Figure 11 shows surface morphologies of the PI dielectrics before plasma discharge aging. As can be seen, there was no significant difference between surfaces of the un-fluorinated PI dielectric and the fluorinated PI dielectric; all of them had smooth surfaces without potholes, except some occasionally distributed micro size dust particles. Cross-section image of the $60 \mathrm{~min}$ fluorinated PI dielectric is given in Figure 11d. It can be seen that a fluorinated layer was formed after fluorination, but the matrix of the dielectric is not affected.
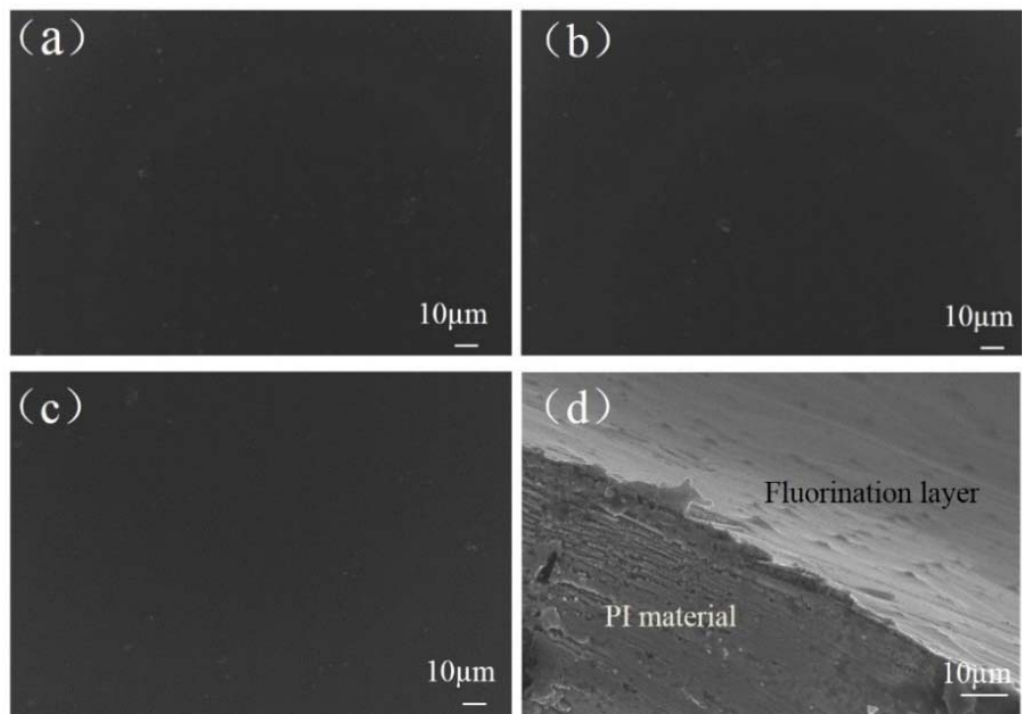

Figure 11. Surface morphologies of the PI dielectrics with fluorination time of (a) $0 \mathrm{~min}$, (b) $30 \mathrm{~min}$ and (c) $60 \mathrm{~min}$, cross-section morphology of (d) 60 min fluorinated dielectric.

Figure 12 shows surface morphologies of the PI dielectrics after $10 \mathrm{~h}$ of plasma processing. All the images were taken in the plasma discharge region around the edge of the exposed electrode. It can be clearly observed that the plasma processing caused distinct changes of surface morphologies. As shown in Figure 12a, the surface of the un-fluorinated PI was severely etched and damaged, many irregular small gibbosities remained on the surface, around which there were lots of bubbles. These gibbosities and bubbles were the PI material and the underlying Si-based adhesive, respectively. 
The isolated gibbosity-like morphology can be ascribed to the space among the randomly distributed micro-discharge, where the active species are generated along the filamentary channel and spatially uneven distributed in the discharge regime [40]. By contrast, Figure 12b,c show that surface morphologies of 30 and $60 \mathrm{~min}$ fluorinated PI dielectrics were more integrated, and the surface roughness was increased after discharge aging. However, no obvious differences in the morphologies can be found between the two surfaces.
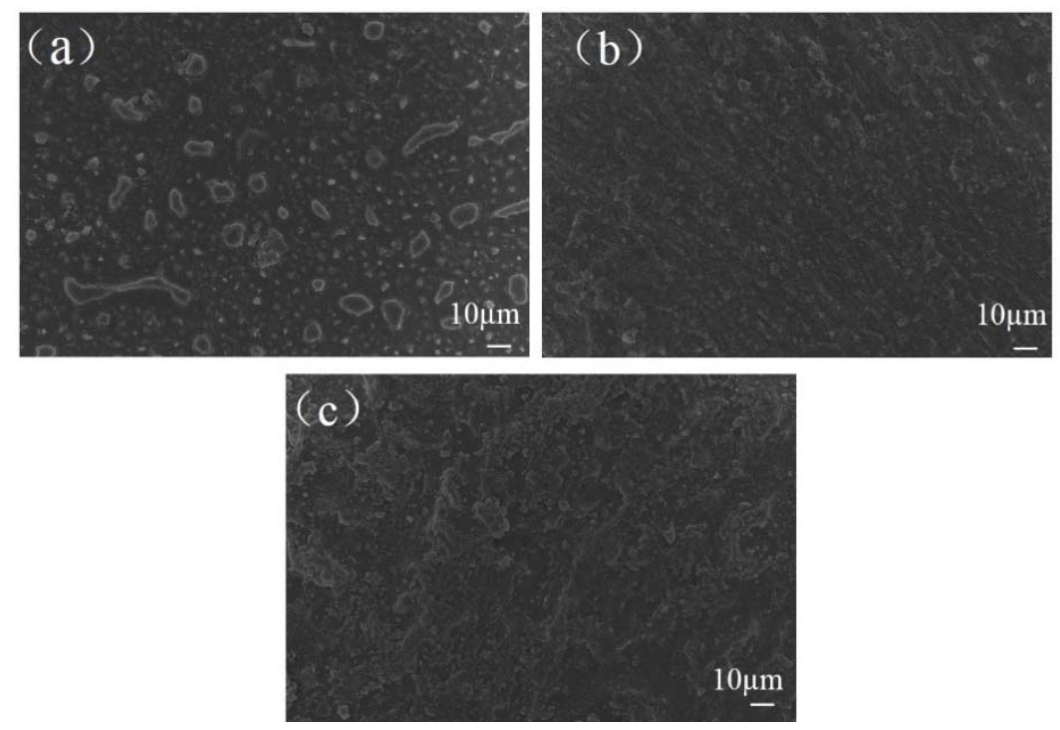

Figure 12. Surface morphologies of the PI dielectrics area after discharge aging: un-fluorinated PI (a), 30 min fluorinated PI (b), 60 min fluorinated PI (c).

XPS analysis was further conducted to investigate changes in the surface chemical composition of un-fluorinated PI and fluorinated PI, before and after plasma processing. As shown in Table 1, for the un-fluorinated PI after $10 \mathrm{~h}$ of plasma processing, the concentrations of both carbon and nitrogen elements decreased sharply, while the concentration of oxygen element increased remarkably from $17.81 \%$ to $38.72 \%$. Besides, a new element (Si) was detected and accounted for $28.57 \%$ of chemical composition; this was due to the fact that long plasma processing caused the exposure of the underlying Si-based adhesive. Compared to un-fluorinated PI, F element was detected on the surfaces of fluorinated PI. When the fluorination time increased from 30 to $60 \mathrm{~min}$, there was no distinct difference between surface chemical composition of $30 \mathrm{~min}(2 \#-0 \mathrm{~h})$ and $60 \mathrm{~min}(3 \#-0 \mathrm{~h})$ fluorinated PI dielectrics. However, after $10 \mathrm{~h}$ of plasma processing, it can be seen that $\mathrm{F}$ element concentration of $60 \mathrm{~min}$ fluorinated PI was about 2.3 times as the $30 \mathrm{~min}$ fluorinated one.

Table 1. Relative chemical composition as determined by XPS before and after plasma processing.

\begin{tabular}{cccccc}
\hline \multirow{2}{*}{ Samples } & \multicolumn{5}{c}{ Chemical composition (at \%) } \\
\cline { 2 - 6 } & $\mathbf{C}$ & $\mathbf{N}$ & $\mathbf{O}$ & $\mathbf{F}$ & $\mathbf{S i}$ \\
\hline 1\#-0h & 78.32 & 3.87 & 17.81 & - & - \\
1\#-10h & 31.96 & 0.75 & 38.72 & - & 28.57 \\
2\#-0h & 54.28 & 3.7 & 14.94 & 27.08 & - \\
2\#-10h & 63.14 & 6.41 & 23.55 & 6.9 & - \\
3\#-0h & 52.14 & 3.88 & 16.91 & 27.07 & - \\
3\#-10h & 51.09 & 7.54 & 25.40 & 15.97 & - \\
\hline
\end{tabular}

In order to examine the changes of functional carbon groups on the surfaces, deconvolution analysis of the C1s peaks were executed; the results are shown in Figure 13 and Table 2. It is noted 
that $\mathrm{C} 1 \mathrm{~s}$ spectra of un-fluorinated PI had four peaks, namely, $\mathrm{C}-\mathrm{C} / \mathrm{C}-\mathrm{H}, \mathrm{C}-\mathrm{N}, \mathrm{C}-\mathrm{O}$, and $\mathrm{C}-\mathrm{N}$, which respectively corresponded to the binding energies of $284.7,285.6,286.3$, and $288.6 \mathrm{eV}$ [24,25]. In addition to the above four peaks, the C1s spectra of surface fluorinated PI incorporated two new peaks, at the binding energies of 287.1 and $289.5 \mathrm{eV}$, which corresponded to the $\mathrm{C}-\mathrm{F}_{\mathrm{n}}$ and $\mathrm{C}-\mathrm{F}$ peaks [26], respectively.

For un-fluorinated PI, the concentrations of $\mathrm{C}-\mathrm{C} / \mathrm{C}-\mathrm{H}, \mathrm{C}-\mathrm{N}, \mathrm{C}-\mathrm{O}$, and $\mathrm{C}=\mathrm{O}$ groups were $69.65 \%$, $11.87 \%, 8.3 \%$ and $10.17 \%$, respectively. After $10 \mathrm{~h}$ of plasma processing, the $\mathrm{C}-\mathrm{C} / \mathrm{C}-\mathrm{H}$ group increased sharply to $85.78 \%$ while the concentration of $\mathrm{C}-\mathrm{N}$ group decreased significantly to $2.64 \%$. Meanwhile, the concentration of $\mathrm{C}=\mathrm{O}$ also showed a sharp decreasing tendency. These changes can be explained by the reactive and heat effect of DBD micro-discharge region on the PI surface. For the fluorinated PI before plasma processing, when fluorination time was increased from 0 to 30 and $60 \mathrm{~min}$, the concentration of $\mathrm{C}-\mathrm{C} / \mathrm{C}-\mathrm{H}$ group decreased sharply from $69.65 \%$ to $61.28 \%$ and $56.44 \%$, while concentration of $\mathrm{C}-\mathrm{F}$ group increased to $13.06 \%$ and $13.49 \%$, and concentration of $C-F_{n}$ group increased to $13.05 \%$ and $13.01 \%$. This result revealed that the $\mathrm{C}-\mathrm{C} / \mathrm{C}-\mathrm{H}$ bonds can be easily broken during plasma processing. Besides, there was no significant concentration variation of fluorine-containing groups when fluorination time was increased from 30 to $60 \mathrm{~min}$, which agreed well with the surface elements composition. After $10 \mathrm{~h}$ of plasma processing, the fluorine-containing group concentration of the $60 \mathrm{~min}$ fluorinated PI $(\sim 22.15 \%)$ was much higher than that of the 30 min fluorinated PI ( 12.84\%).

Table 2. Relative surface chemical bond content of the PI surfaces before and after plasma aging.

\begin{tabular}{ccccccc}
\hline & \multicolumn{5}{c}{ Relative area of different chemical bonds (\%) } \\
\cline { 2 - 7 } Samples & \multicolumn{5}{c}{ C 1s possible groups } \\
\cline { 2 - 7 } & C-C/C-H & C-N & C-O & C=O & C-F & C-F \\
\hline 1\#-0h & 69.65 & 11.87 & 8.3 & 10.17 & - & - \\
1\#-10h & 85.78 & 2.64 & 10.26 & 1.32 & - & - \\
2\#-0h & 61.28 & 4.11 & 4.69 & 3.80 & 13.06 & 13.05 \\
2\#-10h & 71.58 & 5.15 & 5.09 & 2.76 & 7.21 & 5.63 \\
3\#-0h & 56.44 & 4.10 & 5.54 & 7.19 & 13.49 & 13.01 \\
3\#-10h & 57.21 & 5.64 & 9.94 & 5.06 & 10.94 & 11.21 \\
\hline
\end{tabular}
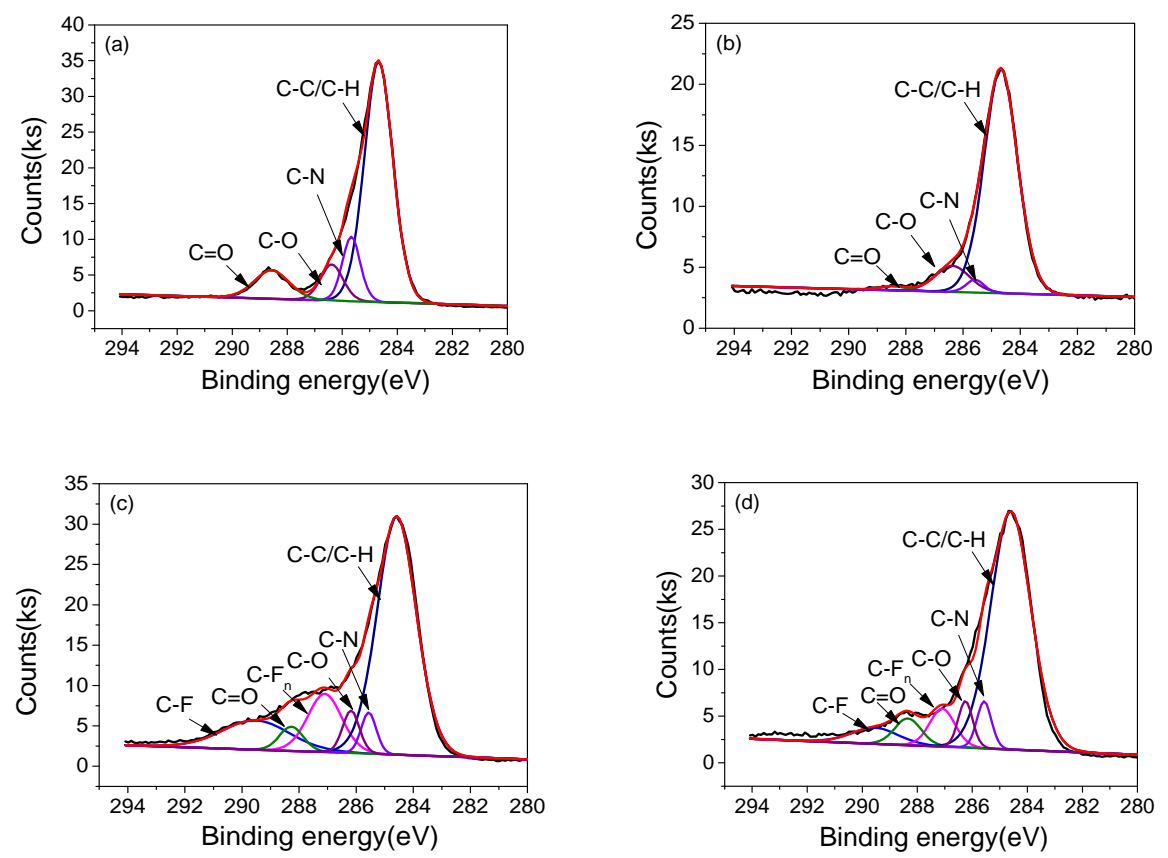

Figure 13. Cont. 

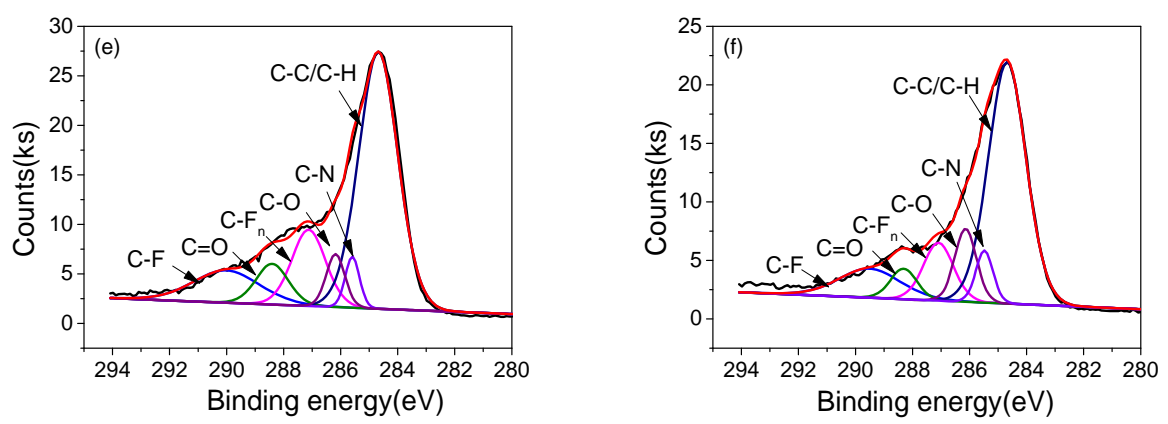

Figure 13. High resolution XPS spectra of C1s peak of (a) unaged and (b) $10 \mathrm{~h}$ aged un-fluorinated PI; (c) unaged and (d) $10 \mathrm{~h}$ aged $30 \mathrm{~min}$ fluorinated PI; (e) unaged and (f) $10 \mathrm{~h}$ aged $60 \mathrm{~min}$ fluorinated PI.

\section{Discussion}

The dielectric lifetime of multi-layered PI-based SDBD device in atmospheric air has an obvious extension through dielectric surface fluorination modification. From surface properties of dielectrics, it can be inferred that two main reasons result in longer dielectric lifetime.

Firstly, the physical effect works, which was reflected in lower surface temperature and increased surface roughness. In aspect of surface temperature distribution, it can be seen from Figure 7 that compared to un-fluorinated PI, the existence of the surface fluorination layer contributed to lower surface temperature, meaning that more effective heat dissipation can be obtained when using fluorinated PI dielectrics. In another aspect of surface morphology, due to an etching effect of plasma discharge, surface roughness increased for the fluorinated PI as shown in Figure 12b,c while the top layer was almost removed for the un-fluorinated multi-layered PI; this indicates that the fluorination layer had positive effects on plasma etching inhibition. In addition, during the plasma process, rougher surface caused a variation of electron movement trajectory and the increase of diffuse reflection [41]. The travel distance of secondary electrons then decreased, that is to say they cannot gain sufficient energy from the electrical field, subsequently, collision energy between the electrons and the dielectric surface was also weakening.

Secondly, the chemical effect works, which was reflected in the graft of fluorine groups. The fluorine groups were introduced into the PI surface after fluorination and led to changes of the surface properties. On the one hand, as shown in Table 1, after $10 \mathrm{~h}$ of plasma discharge, the $\mathrm{F}$ element concentration of $60 \mathrm{~min}$ fluorinated PI was still 2.3 times higher than that of the $30 \mathrm{~min}$ fluorinated PI. Because of the electronegativity of F element, electrons were significantly adsorbed by $\mathrm{F}$ atoms. Consequently, the collisions between the electrons and dielectric surface were restrained. The higher concentration of the F element, more obvious was the restrain effect. On the other hand, it is well known that direct fluorination of polymer results in the disruption of $\mathrm{C}-\mathrm{H}$ bond and a formation of $\mathrm{C}-\mathrm{F}$ and $\mathrm{C}-\mathrm{F}_{\mathrm{n}}$ groups, as $\mathrm{C}-\mathrm{F}$ bond is the strongest single bond in organic chemistry and has bond dissociation energy of $544 \mathrm{~kJ} / \mathrm{mol}$ [42], much higher than that of the $\mathrm{C}-\mathrm{H}$ bond (414 $\mathrm{kJ} / \mathrm{mol})$ [43]. Thus, C-F bond can resist the bombardment of the active species more effectively than the other bonds. As shown in Table 2, after $10 \mathrm{~h}$ of plasma discharge, the C-F group concentration of the $60 \mathrm{~min}$ fluorinated PI remained at $11.21 \%$, about two times higher than that of the $30 \mathrm{~min}$ fluorinated PI.

\section{Conclusions}

In this work, discharge, plasma and dielectric material characteristics of fluorinated PI based SDBD plasma device are studied. During the discharge aging process, the changes of plasma parameters, including gas temperature and electron temperature, are lower for the fluorinated PI based device than the un-fluorinated case, showing that more stable discharge can be obtained when using fluorinated PI as a barrier dielectric. In addition, the dielectric lifetime extends with the fluorination time. The lifetime of the $60 \mathrm{~min}$ fluorinated PI-based plasma device is about three times longer than that of the un-fluorinated 
case at $10 \mathrm{kV}$ applied peak to peak voltage and $6 \mathrm{kHz}$ frequency, which can be explained by surface temperature, roughness, and functional groups changes on the surface of PI. Firstly, after discharge aging, the distinct surface temperature increase of the un-fluorinated PI illustrates that it accumulates more heat energy, which has adverse effects on long-time operation, while no significant temperature variation can be observed on the surface of the $60 \mathrm{~min}$ fluorinated PI. Secondly, the formed rougher surface from fluorinated PI leads to reduction of collision energy between the secondary electrons and dielectric surface in the discharge region. Finally, XPS results show that the fluorine-containing groups are incorporated into the surface of the PI dielectrics; since their bond energy is much higher than $\mathrm{C}-\mathrm{C} / \mathrm{C}-\mathrm{H}$, material degradation effectively slows down during the plasma processing. These results suggest that surface fluorination is a suitable modification method of the dielectric barrier material for application in long lifetime SDBD plasma devices.

Author Contributions: Y.W. conceived and supervised the experiment. D.B. assisted in the device fabrication and characterization as well as wrote the manuscript. Both authors discussed the results and commented on the manuscript.

Acknowledgments: This research was funded by the National Natural Science Foundation of China (51522606, 51502346 and 51407194).

Conflicts of Interest: The authors declare no conflict of interest.

\section{References}

1. Wang, C.; Zhang, G.; Wang, X.; He, X. The effect of air plasma on barrier dielectric surface in dielectric barrier discharge. Appl. Surf. Sci. 2010, 257, 1698-1702. [CrossRef]

2. Kriegseis, J.; Simon, B.; Grundmann, S. Towards in-flight applications? A review on dielectric barrier discharge-based boundary-layer control. Appl. Mech. Rev. 2016, 68, 020802. [CrossRef]

3. Brandenburg, R. Dielectric barrier discharges: Progress on plasma sources and on the understanding of regimes and single filaments. Plasma Sources Sci. Technol. 2017, 26, 053001. [CrossRef]

4. Bian, D.L.; $\mathrm{Wu}, \mathrm{Y}$; Jia, M.; Long, C.B. PI/ $\mathrm{Al}_{2} \mathrm{O}_{3}$ nanocomposite based long lifetime surface dielectric barrier discharge plasma actuator. Sens. Actuat A-Phys. 2017, 267, 90-98. [CrossRef]

5. Meng, X.; Cai, J.; Tian, Y.; Han, X.; Zhang, D.; Hu, H. Experimental Study of Anti-icing and Deicing on a Cylinder by DBD plasma actuation. In Proceedings of the 47th AIAA Plasmadynamics and Lasers Conference, Washington, DC, USA, 13-17 June 2016.

6. Roy, S.; Wang, C. Numerical investigation of three-dimensional plasma actuation for improving film cooling effectiveness. J. Thermophys. Heat Transf. 2013, 27, 489-497. [CrossRef]

7. Kim, H.Y.; Kang, S.K.; Kwon, H.C.; Lee, H.W.; Lee, J.K. Gas temperature effect on reactive species generation from the atmospheric pressure air plasma. Plasma Process. Polym. 2013, 10, 686-697. [CrossRef]

8. Abdelaziz, A.; Ishijima, T.; Seto, T.; Osawa, N.; Wedaa, H.; Otani, Y. Characterization of surface dielectric barrier discharge influenced by intermediate frequency for ozone production. Plasma Sources Sci. Technol. 2016, 25, 035012. [CrossRef]

9. Jiang, N.; Guo, L.; Shang, K.; Lu, N.; Li, J.; Wu, Y. Discharge and optical characterizations of nanosecond pulse sliding dielectric barrier discharge plasma for volatile organic compound degradation. J. Phys. D Appl. Phys. 2017, 50, 155206. [CrossRef]

10. Malik, M.A.; Schoenbach, K.H.; Heller, R. Coupled surface dielectric barrier discharge reactor-ozone synthesis and nitric oxide conversion from air. Chem. Eng. J. 2014, 256, 222-229. [CrossRef]

11. Jeon, J.; Rosentreter, T.M.; Li, Y.; Isbary, G.; Thomas, H.M.; Zimmermann, J.L.; Morfill, G.E.; Shimizu, T. Bactericidal Agents Produced by Surface Micro-Discharge (SMD) Plasma by Controlling Gas Compositions. Plasma Process. Polym. 2014, 11, 426-436. [CrossRef]

12. Pons, J.; Oukacine, L.; Moreau, E.; Tatibouet, J.M. Observation of dielectric degradation after surface dielectric barrier discharge operation in air at atmospheric pressure. IEEE Trans. Plasma Sci. 2008, 36, 1342-1343. [CrossRef]

13. Ennis, C.P.; Kaiser, R.I. Mechanistical studies on the electron-induced degradation of polymethylmethacrylate and Kapton. Phys. Chem. Chem. Phys. 2010, 12, 14902. [CrossRef] [PubMed] 
14. Hanson, R.E.; Houser, N.M.; Lavoie, P. Dielectric material degradation monitoring of dielectric barrier discharge plasma actuators. J. Appl. Phys. 2014, 115, 043301. [CrossRef]

15. Ndong, A.C.; Zouzou, N.; Benard, N.; Moreau, E. Effect of dielectric aging on the behavior of a surface nanosecond pulsed dielectric barrier discharge. IEEE Trans. Dielectr. Electr. Insul. 2013, 20, 1554-1560. [CrossRef]

16. Rigit, A.; Lai, K.; Bong, D. Degradation of a dielectric barrier discharge plasma actuator. In Proceedings of the 9th International Conference on Properties and Applications of Dielectric Materials, Harbin, China, 19-23 July 2009.

17. Kharitonov, A.P. Direct fluorination of polymers-From fundamental research to industrial applications. Prog. Org. Coat. 2008, 61, 192-204. [CrossRef]

18. An, Z.; Chen, X.; Liu, C.; Zheng, F.; Zhang, Y. Significantly reduced fluorination time needed for suppression of space charge in polyethylene by increasing the fluorination temperature. J. Phys. D Appl. Phys. 2012, 45, 385303. [CrossRef]

19. Tressaud, A.; Durand, E.; Labrugere, C.; Kharitonov, A.; Kharitonova, L. Modification of surface properties of carbon-based and polymeric materials through fluorination routes: From fundamental research to industrial applications. J. Fluorine Chem. 2007, 128, 378-391. [CrossRef]

20. An, Z.; Yang, Q.; Xie, C.; Jiang, Y.; Zheng, F.; Zhang, Y. Suppression effect of surface fluorination on charge injection into linear low density polyethylene. J. Appl. Phys. 2009, 105, 13. [CrossRef]

21. An, Z.; Liu, C.; Chen, X.; Zheng, F.; Zhang, Y. Correlation between space charge accumulation in polyethylene and its fluorinated surface layer characteristics. J. Phys. D Appl. Phys. 2011, 45, 35302-35309. [CrossRef]

22. Du, B.X.; Li, J.; Du, W. Dynamic behavior of surface charge on direct-fluorinated polyimide films. IEEE Trans. Dielectr. Electr. Insul. 2013, 20, 947-954. [CrossRef]

23. Du, B.X.; Li, J.; Du, H.; Yin, Y. Effect of surface fluorination on space charge behavior in multilayered polyimide films. IEEE Trans. Dielectr. Electr. Insul. 2014, 21, 1817-1823. [CrossRef]

24. Hur, M.; Kang, W.S.; Lee, J.O.; Song, Y.H. Surface treatment of polyimide substrates using dielectric barrier discharge reactors based on 1-shaped electrodes. Plasma Chem. Plasma Process 2015, 35, 231-246. [CrossRef]

25. Shao, T.; Zhang, C.; Long, K.; Zhang, D.; Wang, J.; Yan, P.; Zhou, Y. Surface modification of polyimide films using unipolar nanosecond-pulse DBD in atmospheric air. Appl. Surf. Sci. 2010, 256, 3888-3894. [CrossRef]

26. Wang, R.; Zhang, C.; Liu, X.; Xie, Q.; Yan, P.; Shao, T. Microsecond pulse driven Ar/CF 4 plasma jet for polymethylmethacrylate surface modification at atmospheric pressure. Appl. Surf. Sci. 2015, 328, 509-515. [CrossRef]

27. Miron, C.; Hulubei, C.; Sava, I.; Quade, A.; Steuer, A.; Weltmann, K.; Kolb, J.F. Polyimide Film Surface Modification by Nanosecond High Voltage Pulse Driven Electrical Discharges in Water. Plasma Process. Polym. 2015, 12, 734-745. [CrossRef]

28. Dong-liang, B.; Yun, W.; Mia, J. Characterization of surface dielectric barrier discharge (SDBD) based on PI/Al2O3 nanocomposite. Plasma Process Polym. 2018, e1700236. [CrossRef]

29. Tirumala, R.; Benard, N.; Moreau, E.; Fenot, M.; Lalizel, G.; Dorignac, E. Temperature characterization of dielectric barrier discharge actuators: Influence of electrical and geometric parameters. J. Phys. D Appl. Phys. 2014, 47, 255203. [CrossRef]

30. Joussot, R.; Hong, D.; Rabat, H.; Boucinha, V.; Weber-Rozenbaum, R. Thermal Characterization of a DBD Plasma Actuator: Dielectric Temperature Measurements using Infrared Thermography. In Proceedings of the 40th Fluid Dynamics Conference and Exhibit, Chicago, IL, USA, 28 June-1 July 2010.

31. Kriegseis, J.; Möller, B.; Grundmann, S.; Tropea, C. Capacitance and power consumption quantification of dielectric barrier discharge (DBD) plasma actuators. J. Electrosta. 2011, 69, 302-312. [CrossRef]

32. Dave, H.; Ledwani, L.; Nema, S.K. Surface modification by atmospheric pressure air plasma treatment to improve dyeing with natural dyes: An environment friendly approach for leather processing. Plasma Chem. Plasma Process 2016, 36, 599-613. [CrossRef]

33. Nassar, H.; Pellerin, S.; Musiol, K.; Martinie, O.; Pellerin, N. $\mathrm{N}_{2}{ }^{+} / \mathrm{N}_{2}$ ratio and temperature measurements based on the first negative $\mathrm{N}_{2}{ }^{+}$and second positive $\mathrm{N}_{2}$ overlapped molecular emission spectra. J. Phys. D Appl. Phys. 2004, 37, 1904. [CrossRef]

34. Mahoney, J.; Zhu, W.; Johnson, V.; Becker, K. Electrical and optical emission measurements of a capillary dielectric barrier discharge. Eur. Phys. J. D 2010, 60, 441-447. [CrossRef] 
35. Lianzhu, Z.; Shuxia, Z.; Xiulan, M. Characterization of nitrogen glow discharge plasma via optical emission spectrum simulation. Plasma Sci. Technol. 2008, 10, 455-462. [CrossRef]

36. Wu, Y.; Li, Y.; Jia, M.; Song, H.; Su, C.; Pu, Y. Experimental investigation into characteristics of plasma aerodynamic actuation generated by dielectric barrier discharge. Chin. J. Aeronaut. 2010, 23, 39-45.

37. Zhu, X.M.; Pu, X.K. Determining the electron temperature in inductively coupled nitrogen plasmas by optical emission spectroscopy with molecular kinetic effects. Phys. Plasmas 2005, 12, 103501. [CrossRef]

38. Wu, Y.; Li, Y.; Jia, M.; Song, H.; Liang, H. Optical emission characteristics of surface nanosecond pulsed dielectric barrier discharge plasma. J. Appl. Phys. 2013, 113, 033303. [CrossRef]

39. Luo, S.C.; Denning, C.M.; Scharer, J.E. Laser-rf creation and diagnostics of seeded atmospheric pressure air and nitrogen plasmas. J. Appl. Phys. 2008, 104, 013301. [CrossRef]

40. Wagner, H.E.; Brandenburg, R.; Kozlov, K.V.; Sonnenfeld, A.; Michel, P.; Behnke, J.F. The barrier discharge: Basic properties and applications to surface treatment. Vacuum 2003, 71, 417-436. [CrossRef]

41. Chen, S.; Wang, S.; Wang, Y.; Guo, B.; Li, G.; Chang, Z.; Zhang, G. Surface modification of epoxy resin using $\mathrm{He} / \mathrm{CF}_{4}$ atmospheric pressure plasma jet for flashover withstanding characteristics improvement in vacuum. Appl. Surf. Sci. 2017, 414, 107. [CrossRef]

42. Lemal, D.M. Perspective on fluorocarbon chemistry. J. Org. Chem. 2004, 69, 1-11. [CrossRef] [PubMed]

43. Blanksby, S.J.; Ellis, G.B. Bond dissociation energies of organic molecules. Acct. Chem. Res. 2003, 36, $255-263$. [CrossRef] [PubMed]

(C) 2018 by the authors. Licensee MDPI, Basel, Switzerland. This article is an open access article distributed under the terms and conditions of the Creative Commons Attribution (CC BY) license (http://creativecommons.org/licenses/by/4.0/). 